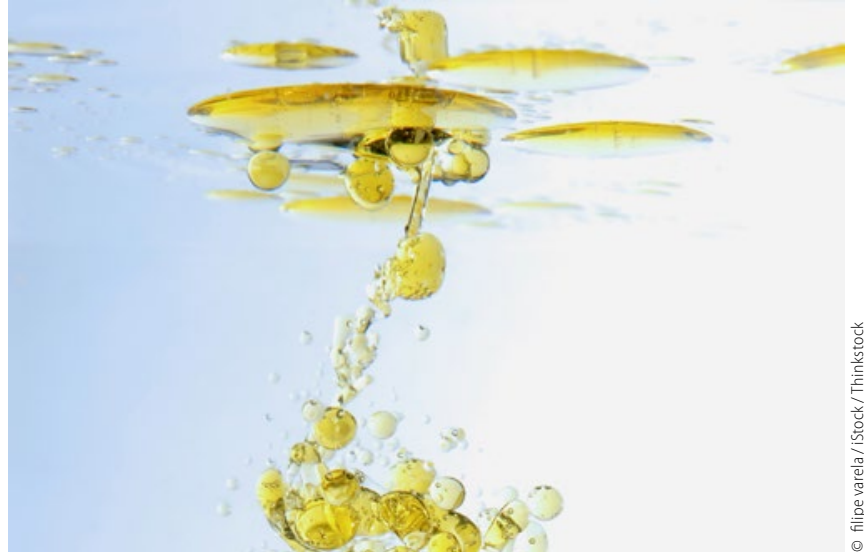

Studie: Ölziehen hilft bei Gingivitis

\section{Ölspülung versus Standardspülung}

Dem Ölziehen wird in der Alternativmedizin seit Jahrhunderten eine heilende oder lindernde Wirkung bei bestimmten Krankheiten nachgesagt. Was die Wirksamkeit einer solchen Ölkur auf Zahnfleischerkrankungen betrifft, gehen die Meinungen weit auseinander. Indische Wissenschaftler haben nun offenbar Belege gefunden, dass die alternativmedizinische ayurvedische Heilmethode einen antibakteriellen Effekt hat und so bei Zahnfleischentzündungen helfen kann.

Wie die Forscher des Meenakshi Ammal Dental College and Hospital im Indian Journal of Dental Research schreiben, haben sie zehn an Gingivitis erkrankte Patienten einmal am Tag eine Ölkur mit Sesamöl machen lassen. Dazu wird kaltgepresstes Öl etwa zehn bis 20 Minuten langsam im Mund hin und her bewegt, danach ausgespuckt und mit Wasser nachgespült. Eine Kontrollgruppe bekam eine Chlorhexidin-haltige Standardlösung.

Nach zehn Tagen zeigte sich, dass hinsichtlich Plaque und Gingivitis eindeutige Verbesserungen bei der Gruppe nachzuweisen waren, die täglich ihren Mund mit Öl spülte.

mar

\section{Kurzfilmwettbewerb von ProDente}

\section{Zähne zeigen}

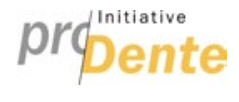

Die Menschen brauchen sie zum Essen, zum Sprechen und für die allgemeine Gesundheit: die Zähne. Mit einem Kurzfilmwett-

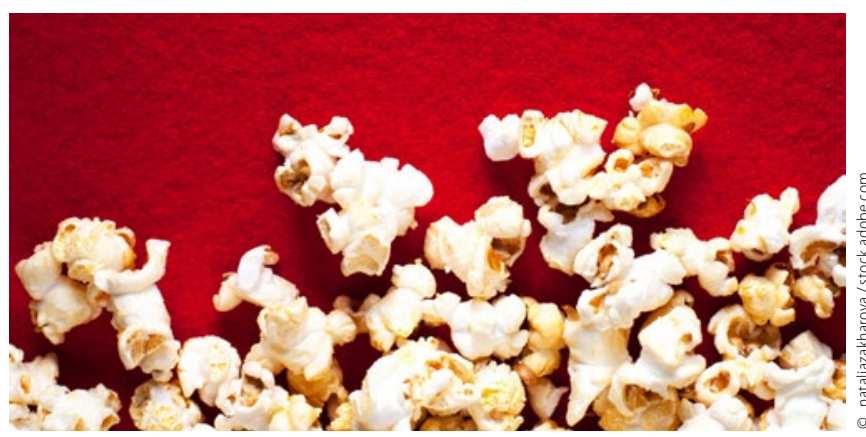

\section{Mandeln sollen vor Zahnerkrankungen schützen}

\section{Kauen statt gurgeln}

Yoga, Meditation, Ayurveda - viele so genannte alternative Lebensformen und Heilmethoden kommen aus Indien, womöglich auch eine alternative Prophylaxe gegen Zahnerkrankungen. Chinesische Forscher haben nämlich herausgefunden, dass die indische Mandel, terminalia chebula, Zähne und Zahnfleisch schützen und damit ein alternatives antimikrobielles Mittel in puncto Mundgesundheit sein soll. Terminalia chebula enthält demnach antibakterielles Ethanol und tötet so Keime im Mund ab. Der Entstehung von Plaque und Parodontitis könne damit vorgebeugt und Parodontalerkrankungen besser behandelt werden, berichten die Forscher im Onlinemagazin BMC Complementary and Alternative Medicine.

Damit könnte die indische Mandel gerade auch in Ländern, in denen viele Menschen kaum Zugang zu Zahnärzten oder Möglichkeit zur Mundhygiene haben, Zahnerkrankungen vorbeugen. Und als Alternative zu Mundspüllösungen mit Chlorhexidin dienen, wie die Forscher schreiben.

Weitere Untersuchungen seien bis dahin jedoch erforderlich, um die Substanzen zu identifizieren und zu isolieren, die für den pharmazeutischen Gebrauch von Nutzen sind.

mar

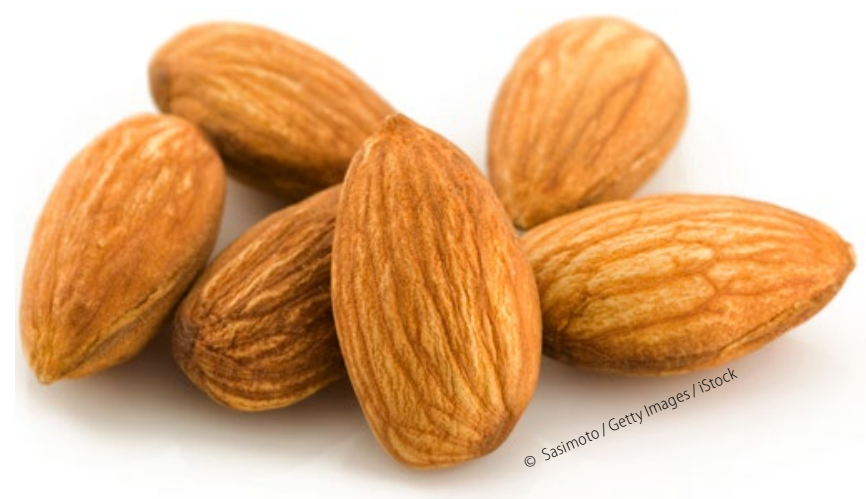

bewerb unter dem Motto „Zähne gut - alles gut" möchte die Initiative ProDente vor allem auch Jugendliche und junge Erwachsene über den Wert der Zähne aufklären.

In den Spots kann es um die Zahnpflege, die Funktion der Zähne oder die Produktion von Zahnersatz gehen. Die Beiträge von maximal fünf Minuten Länge dürfen dabei gerne witzig oder musikalisch aufbereitet sein, aber auch ernst, appellativ oder provokativ.

Den Gewinnern des Wettbewerbs winken insgesamt 6.000 Euro Preisgeld, Einsendeschluss ist der 31. August 2017. Mitmachen können „Studenten an Filmhochschulen und Medienakademien, freie Filmkünstler, Kreative, Du“, heißt es auf der Webseite, und dort gibt es auch die Details:

http://kurzfilmwettbewerb.prodente.eu/ 